\title{
On Value Analysis about Culture Transfer Effect of Private Enterprises Xu Yanjun
}

Zhejiang Dongfang Vocational and Technical College 325011

Keyword: Enterprise culture transfer, space strategy, value, and ecological effect.

\begin{abstract}
Selection effect of the strategy development space of private enterprises usually is depending on application to strategy and pattern of its cultural background. Social awareness and effect value of enterprise culture transfer lies on survival sense of its space transfer strategy, and the selection of self strategy space not only is the requirement of its own development, but also should put into the consideration of the intervening or encounter and even traction or implantation of business management and operational behavior, and impact on regional social economy and culture and social economic and cultural construction. The relationship between Cultural background and reality reform can be integrated into regional society culture, and it can form the strategic culture thinking and ideas of the enterprise independent operation and management behavior, and then an enterprise development environment can be formed.
\end{abstract}

\section{Introduction: Relationship between enterprise transfer and enterprise culture}

More than 30 years' reform and opening up has produced Zhejiang entrepreneur that is always recognized as a group that is the most active and very good at grasping market opportunity in market economy. Its biggest characteristic is able to comply with the law of market development and changes, and the expansion and changes of government's adjustment for industry plan, search for chance for growth of enterprise strategy through design of suitable development mode.

Strategy is life of enterprise, culture is the nucleus of enterprise life, while the enterprise culture that is easy to melt with social culture has determined the survival value of enterprise strategy. It cannot be difficult to find its excellency of success if we reasonably inspect the economic phenomena of trans-regional transfer of private enterprises in Zhejiang. Therefore, we should firstly study the soul value and sense of enterprise culture during the process of enterprise transfer and development when we study the enterprise transfer strategy's value and sense of development.

1.1 The inertia value of enterprise culture transfer

At present, the private enterprise transfer of Zhejiang has shown changes from individual transfer to industrial group transfer. As the cross-regional transfer of enterprises search for expansion of strategic space, the demand on expansion of enterprise culture will have to clash and conflict with the social traditional culture of the transfer destination. The basic property of culture has taken on a formulary of thought and behavior of regional group, when the action of enterprise transfer has effect on the ecology of the original place's social culture, it still affects more on the behavioral value of the ecological culture of the destination. Based on the accumulation during the growth process of enterprise, its culture has formed belief in enterprise strategy that will become the code of conduct for staffs' behavioral method, while all of these will make enterprise develop based on the respect for the social, environment and culture of the transfer destination.

After the enterprise is successful in transfer, the value property of social environment culture is highlighted in the process of integration of industry value chain, while the advanced culture and new value concept of enterprise in transfer bring changes in the destination's life and economy, it also brings impacts on its habit and life style. Therefore, enterprises must search to melt with the destinations' culture, led by the enterprise culture, actively communicate and coordinate with local culture, thus establish a long-term relationship of trust based on the cultural identity gradually, in order to construct new regional culture while affecting the local culture by the demonstrative effect of enterprise culture.

1.2 The selection basis for enterprise culture transfer strategy

After the enterprise makes decision on the transfer strategy, it must indicate the original survival 
environment and condition have occurred changes that are difficult to maintain, thus as a result of the enterprise's active compromise. From the aspect of transfer enterprise itself, the key is to be sensitive enough to the actual survival environment, and can resolve completely through closely combining the balanced relationship between enterprise internal resource conditions and features as well as external environment, this is the special thought model of enterprise transfer.

Yufei, the expert of private enterprise, has ever said that the problem private enterprises face now is neither the capital, nor the quality of product, but the quality managers. Whether the enterprise can continue to improve the vitality of itself through the initiative behavior, whether it can get wider survival space, whether the strategy and method of enterprise management can form special enterprise culture as a carrier melting with social culture through enterprise product and operation content, and get wide recognition and support from market, to a large extent depending on the strategic quality of negotiation and level of entrepreneurs as well as the inclusive and embedment of enterprise culture construction.

\section{The ecological effect of enterprise culture transfer}

The new economic geography tries to interpret the change factors of enterprise strategic space through the change of nucleus-periphery structure; The culture ecology emphasizes the balanced relation between the concentration and proliferation of enterprise culture. Both of them have offered a certain theoretic basis for the adjustment of enterprise strategic space structure in the aspect of theoretical explanation, meanwhile, have brought changes in the internal forces of enterprise, thus enterprises are actively adapting to new ecological environment, while they adjusting the influential factors.

2.1 Transfer of enterprise culture is the embody of value of selection effect of enterprises

Analysis from the aspect of the influential factor of selection effect of enterprise, based on the self negotiation of enterprise strategy survival environment

and self selection of ecological environment, it is shown as spillover effect and implant effect when the enterprise culture is getting used to the regional culture, the influential culture effect released from transfer must become the important factor affecting the regional social culture.

The transfer of private enterprises is the strategic decision under dynamic environment, not only the enterprise's behavior will be considered, but also the connotation of social culture implanted in these behaviors, this embeddness is also the basic stone for transfer enterprise to build key ability. The development of regional culture and the purpose of implanting are to get strategic resources, realizing the sustainable growth of enterprise. However, the selection of strategic space of enterprise is not only the need of enterprise's self development, we should think more about how the behavior of enterprise management and operation involves in, clashes with or even leads and implants into the regional culture, thus affect the construction of regional economic culture and national social economic culture.

The practical transfer of private enterprise expands the practical culture into the region being invested efficiently, the results pursued make the destination enjoy the economic benefit brought in by the original area on the one hand, on the other hand, the destination can feel and learn that the social development needs a social economic culture of strong desire for survival and motivation for benefit, thus making the regional economic culture present impulse of dynamic reform.

2.2 Transfer of enterprise culture is the ecological condition of enterprise realizing its value

The thought determines strategy and culture is the base of pattern. The successful transfer of private enterprises is based on the strategic thought and behavioral method during the cultivation of enterprise culture, such as the enterprise uses overspill strategy to make enterprise culture succeed in breaking away from the original market, meanwhile it implants strategy and intervene the destination by way of melting, melting into regional culture in the process of cultural clash, and producing cultural integration based on the advantage of the enterprise's cultural characteristic, thus giving birth to a new cultural type of regional society and economy.

Enterprise forms an interactive ecological system through the exchange between cultural energy and behavioral information and social environment, thus determine its ecological position in the 
aspect of strategic resources. This is not only the cultural factor that enterprise searches strategic space transfer, but also the ecological factor that enterprise gets used to environment.

Mark Granovetter, American sociologist, emphasizes in his social economic theory that the economic activities of enterprises are affected by the social and cultural system as well as value system, and "embedded into" the social system or network; the survival and development of enterprise depend on social environment's basic trust for enterprise, while this kind of trust originates from the system culture and behavioral culture in the process of enterprise operation and management, and this culture can be accepted and liked only if this culture is implanted into the regional social structure and cultural environment.

2.3 Transfer of enterprise culture is the key value presentation of enterprise space strategy

The implanting of private enterprise culture transfer is integration of connotation of enterprise background culture of enterprise behavior and the regional society culture, and it is embodied as the nucleus value of the behavior of enterprise culture transfer. It is completely depending on the core value expression of enterprise culture in the transfer space strategy whether the enterprise transfer behavior can succeed.

The process of enterprise transfer is the process of enterprise culture transfer, and also the process when the economic and social culture in the original environment transfers with enterprise culture as carrier, and its behavioral expression must show some features of the culture in the original area. Therefore, the process of implanting is the process of two kinds of culture clash into and melt with each other, in the beginning of implanting, the freshness and vitality brought from the original culture are the main reason to guarantee the successful stay and development of enterprise transfer. However, as the impact of enterprise culture and original society culture on the culture of implanting area, the clash between two cultures will become an obstacle to the sustainable survival and development of enterprise. Therefore, the regional society of enterprise cultural connotation must be adjusted by implanting, implant the enterprise culture into the real social regional culture through reform between the cultural background and the relation in reality, forming strategic cultural thought and idea of enterprise independent operation and management. Because only the enterprise culture implanted in the regional culture background can form strategic development environment that the enterprise's survival is depending on.

\section{Judgment of social value of enterprise culture transfer}

The extroversion of enterprise culture depends on the strategic choice and judgment of enterprise, this is embodied as the ecological behavior of environment cultivated during the enterprise transfer; The introversion of enterprise culture depends on the market behavior guided by the survival idea of enterprise strategy. Look at the survival characteristics of enterprise succeeds in transfer; the judgment of social culture value of enterprise culture transfer is depending on the integration relation between the cultural property of enterprise survival environment and the characteristic of the enterprise culture itself.

3.1 The social cognition of enterprise culture transfer

The design of strategic consciousness of culture and ability to thought is the core quality of the corresponding relations between transfer enterprise and the enterprise culture itself and the environment. The elements required for survival of enterprise transfer are various, but the social acquaintance of enterprise culture transfer is the critical content. The core of enterprise culture transfer is the specific presentation of the comprehensive quality of enterprise spirit, enterprise operation quality as well as enterprise market behavior. In a sense, the social cognition of enterprise culture transfer decides the method that enterprise adapts to environment and the characteristic of its image, and usually decides the value judgment and presentation of enterprise cultural strategic property.

To succeed in transfer, we must improve survival idea, and improve culture to win support! The excellent enterprise culture and social regional economic culture are unified to a large extent, the core method of market survival in the process of enterprise transfer isn't the scheme or execution of mode or operation strategy, but the cultural connotation and behavioral value shown up by 
enterprise behavior. Excellent transfer enterprise will actively pursue regional culture's approval, and implant acculturation based on the earnest understanding of regional culture and by way of the enterprise culture's advancement, thus get regional culture's trust and support, and win development space.

\subsection{The integration value of enterprise culture transfer}

It is sure that the transfer enterprise is different from the destination's social culture in the aspect of social background and cultural image, however, this is just where the value of enterprise culture relies in, and the culture medium of enterprise melting with regional culture, as well as the catalyst for enterprise culture transferring integrated value.

The unique feature inborn in enterprise culture must affect the environment through enterprise behavior, the historic tradition and the feature of management with social and cultural gene of the original region that enterprise culture contents have shown strong cultural impact while they are melting into the economic and social culture of destination gradually. As the further in-depth of market economy, the cultural property of market shows strongly, the transfer enterprise, with different enterprise culture, has shown obviously different behavioral method while adapting to the environment, thus making the enterprise culture transfer show different characteristics. However, the clash and integration of cultural property in the process of transfer are the common subject. "Xunzi-Codes of Conduct for Monarchs": "Transfer with it and change while observe it." Because there is difference in the original cultural resources of enterprise, and the magnification of enterprise culture transfer is also different, the differences in property of regional social culture, form, value cognition and appraisal standards are differences in aspect and method of transfer enterprise culture implanting, all of them are combing and adjusting themselves by variable strategy in the behavioral method while they are adapting to environment, thus realize the social and market value of enterprise culture transfer.

\section{Conclusion}

Enterprise culture is the successful behavioral art and spiritual wealth created in the historic process of enterprise development. However, due to different social and cultural environment of enterprise, different enterprise survival strategies, different human resources background, enterprises are different from each other, and the enterprise cultural connotation, the relations between the manifestation method of cultural behavior and the social and economic culture are also different from each other; The enterprise cultural transfers formed by enterprise transfer are different in conditions and characteristics of cultural resources, and the cultural competition and influential potential produced are different from the market and social effect formed by behavioral pose and environmental resources integration resources in melting the social regional economy and culture. The reasonability and integration of enterprise culture are the strategic basis for the creation of social environment, propagation of cultural information, ecological feature of enterprise culture and integration with ecological conditions regional culture and implanting of cultural ecology, the unique value connotation of enterprise culture can make the regional culture environment improve to some extent, and can become the potential resources of integration and harmonious coexistence.

The strategic of enterprise culture transfer is based on the original society cultural soil, in the transfer bearing the background culture, while pursue the stability of transfer destination, the stability of enterprise culture and its background culture shall be highlighted more. Mr. Henry Mintzberg has ever said: "The basis of concept of strategy is just stability rather than change". Melting with regional culture by unconsciously influence, realize the social value of stability of enterprise culture, through the active and positive strategic and cultural integration of enterprise. The integrative development of social culture need be led and intervened by advanced culture, the improvement and progress of the regional innate culture also need be led and inspired by quality culture, therefore, the value of intervention and inspiration during enterprise culture transfer determine the environmental effect value of mechanism of enterprise culture transfer effect and also are the basic conditions for realizing the development of strategic space transfer.

The cultural value contained in the operating strategy of enterprise obviously has the tendency of 
profit, while the cultural property bearing the strategic life of enterprise emphasizes more on the life features of social environment of enterprise behaviors. The private enterprise culture usually has a relation of blood with the culture of its traditional survival environment, the strategic design of private enterprise culture must make the culture of private enterprise adapt to environment actively, therefore, the selection of the survival environment of enterprise especially embodies the excellent cultural form of learning, forming tremendous drive for the mechanism innovation and the behavior guidance of core value of enterprise culture transfer.

\section{Fund Program}

Periodic Achievement of Research topic of social science union Zhejiang province of Year 2014 "Study on Culture Transfer Effect Mode of Private Enterprise Strategic Space Transfer of Zhejiang", Subject Number: 2014B085

2 Author introduction: Xu Yanjun, Male, Assistant Professor of Zhejiang Dongfang Vocational and Technical College Research direction: The Strategy Management of Enterprise

\section{Reference}

[1] Bamberger. The Theoretic Basis of Enterprise Strategic Decision[J]. Digest of Foreign Social Sciences.1983 09

[2] Wang Yunqi. Discussion on Management through "China-style" Culture[N]. China Human Resource Network

[3] Fa Xiaoying. Xin MinJia. Negative Transfer of Culture and Moderate Cultural Empathy in Cross-cultural Communication[J]. Journal of Academic BBS. 2011.05

[4] Translated by (America), James.F.Moore. Liangjun and so on. The Decline and Fall of Competition[M]. Beijing Publishing House. 1990

[5] Wang Jingang. The Change and Unchange of Enterprise Culture[N]. Beijing Science and Technology News. 2000

[6] Huang Pin. Strategic Research of Innovative Enterprise Development [D]. Tianjin University. 2003

[7] Zhang Enyuan. Preliminary Thought and Practice about Enterprise Culture Construction of Shanghai Construction Bank [A]. Proceedings of Shanghai Commercial Culture[C].1995

[8] Liu Baohua. The Cultural Power and Cultural Transfer of Enterprise Management. [J]. Journal of Chifeng Institute. 2013.13 